UCRL-53668

Distribution category UC-15

UCRL -53668

DE86 002361

\title{
DOE Site-Specific Threat Assessment
}

A Study by the San Francisco Operations Office of the Department of Energy in collaboration with

Lawrence Livermore National Laboratory,

Livermore, California, and Applied Decision Analysis, Incorporated, Menlo Park, California

D.J. West, R.A. Al-Ayat, and B.R. Judd

Manuscript Date: July 12, 1985

\section{LAWRENCE LIVERMORE NATIONAL LABORATORY}

University of California - Livermore, California - 94550 


\section{Contents}

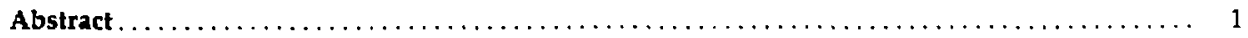

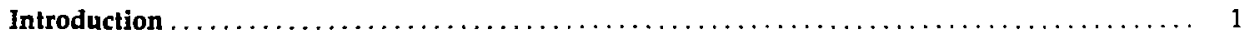

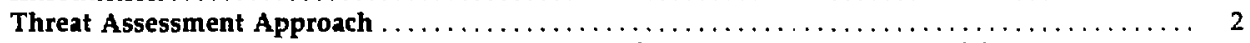

Development of the Threat Assessment Approach and the Quantitative Model $\ldots \ldots \ldots \ldots \ldots 2$

Threat Likelihood Assessment $\ldots \ldots \ldots \ldots \ldots \ldots \ldots \ldots \ldots \ldots \ldots \ldots \ldots \ldots \ldots \ldots, \ldots \ldots \ldots$

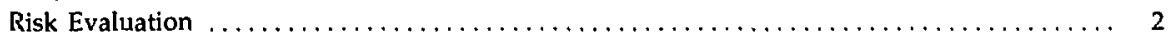

Establishment of a Data Base $\ldots \ldots \ldots \ldots \ldots \ldots \ldots \ldots \ldots \ldots \ldots \ldots \ldots \ldots \ldots \ldots \ldots$

Validation of the Threat Assessment Data $\ldots \ldots \ldots \ldots \ldots \ldots \ldots \ldots \ldots \ldots \ldots \ldots \ldots \ldots \ldots$

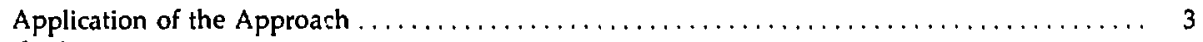

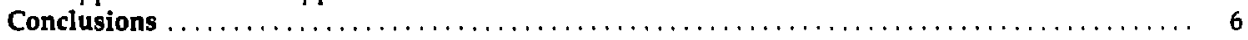

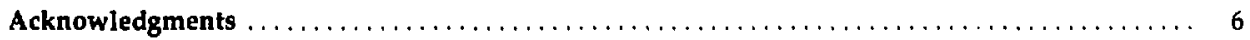

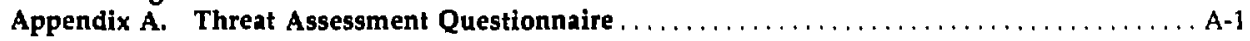

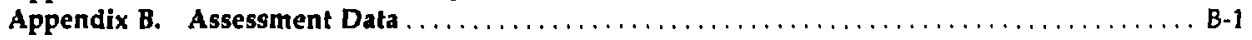




\title{
DOE Site-Specific Threat Assessment
}

\begin{abstract}
A facility manager faced with the challenges of protecting a nuclear facility agains potential threats must consider the likelihood and consequences of such threats, know the capabilities of the facility safeguards and security systems, and make informed decisions about the cost-effectiveness of safeguards and security upgrades. To help mee! these challenges, the San Francisco Operations Office of the Department of Energy, in conjunction with the Lawrence Livermore National Laboratory, has developed a sitespecific threat assessment approach and a quantitative model to improve the quality and consistency of site-specific threat assessments and resultant security upgrade decisions at sensitive Department of Energy facilities.
\end{abstract}

\section{Introduction}

Protecting nuclear facilities against potential threats is a complex problem for facility managers. They must consider many factors. These factors include the potential of the threats, the consequences, the effectiveness of safeguards and security systems, and the costs of upgrading these systems to neet changing conditions.

Potential threats can vary from highly unlikely, catastrophic external attacks that require skilled quasi-military response to frequent, nonviolent protests that require a much different security posture. As political conditions change, however, the likelihood and nature of these potential threats may also change.

To counter the broad spectrum of potential threats, facility managers rely on diverse safeguards and security measures. Some of these measures are exercised routinely, and it is feasible to test some aspects of their effectiveness. Others cannot be tested except in an actual confrontation. It is this inability to pretest the effectiveness of safeguards and security measures that creates uncertainty about the effectiveness of the chosen security systems.
Deciding how to upgrade safeguards and security systems involves difficult trateoffs between benefits and costs. Given the broad range of threats, the facility manager must decide where to commit additional resources and what improvements are justified.

To help meet these challenges, the San Francisco Operations Office of the Department of Energy (DOE-SAN), in conjunction with the Lawrence Livermore National Laboratory (LLNL), has developed an approach for assessing the likelihood of potential threats at their sensitive facilities. The approach, which we term the threat assessmem approach, incorporates a variety of factors systematically and quantitatively, improving the consistency and quality of threat assessments. Further, the threat likelihood results can be combined with information on the consequences of potential threats and the effectiveness of safeguards and security measures to provide an overall evolution of risk at the facility. The threat assessment and risk evaluation can then be used to determine the most efficient allocation of safeguards and security resources. 


\section{Threat Assessment Approach}

The threat assessment approach was developed and applied in four phases:

1. Development of the threat assessment approach and the quantitative model.

2. Establishment of a data base using SAN and LLNL judgment.

3. Validation of the threat assessment data by eliciting expert opinion outside SAN and LLNL.

4. Application of the quantitative model to describe site-specific threats, to evaluate the effectiveness of current safeguards, and to select appropriate security measures.

\section{Development of the Threat Assessment Approach and the Quantitative Model}

The threat assessment approach begins with the characterization of potential threats. DOE Headquarters provides threat guidance, which describes generic threats that must be considered when designing safeguards and security systems or when assessing their performance. Operations offices apply these generic guidelines to chiracterize these threats and to ensure that adequate protection is provided. In addition to these generic threats, the operations offices must consider localized th wats that may pose additional danger to their facilities. Their threat assessments must, therefore, consider site-specific factors, as well as changing conditions that may affect any local threat.

\section{Threat Likelihood Assessment}

To ensure that such threat assessments are conducted systematically, we developed a quantitative model for assessing the relative likelihood of potential threats at applicable DOE sites. The model computes the likelihood of potential threats on the basis of input data regarding possible adversaries, their primary motivations, their goals and resources, and the sites or targets within the nuclear facility that they might choose to accomplish their goals.

Initially, we considered 13 categories of adversaries. After cur preliminary assessment, we condensed the list to five adversaries with distinct characteristics. We also considered eight possible motivations and five goals:

\begin{tabular}{lll}
\hline Adversaries & Motivations & \multicolumn{1}{c}{ Goals } \\
\hline - Terrorists & - Monetary gain & - Penetrate site \\
- Foreign & - Embarassment & - Sabotage \\
governments & - Extortion & - Atquire special \\
- Criminals & - Stop nuclear & nuclear material \\
- Exiremists & - Politicai power & (SNM) \\
- Nuisances & - Develcp weapon & - Steal nuclear \\
& - Reverge & iveapon \\
& - Intelligence & - Guin information \\
\hline
\end{tabular}

We assessed the relative likelihood of each motivation for each adversary. Then we assessed the likelihood that an adversary with a particular motivation woukd attempt to accomplish each possible goal at a specific site. These assessments were later combined in a computer model to produce a quantitative statement of the relative likelihood of each potential threat.

The threat likelihood assessnent approach provides a logical framework for determining why some threats are more likely than others. Since the model is implemented on a portable computer, it can be used "on the spot" to identify which expert judgments are most crucial in ctetermining the relative likelihoost of various threats. In addition, the model provides important input to the evaluation of overall risk at a facility, as explained in the following section.

\section{Risk Evaluation}

The likelihood of potential threats is one key input in evaluating overall risk. The other key inputs are information about the capabilities of safes. rds and security systems and the rel..ive consequences should these systems fail to defeat the adversary. Specifically, the risk evaluation considers what would happen if adversaries were to accomplish their goals, how the consequences could vary if there are multiple targets or buildings at a particular facility or site, and the probability of defeating the adversary's attempts to accomplish each goal.

To aid in evaluating the risks, opinions are elicited from appropriate persons deemed authorities in their particular subject areas. The opinions on each factor are then combined to produce quantitative statements of the overall risk at a given site. The quantitative ; isk results are provided in the form of bar graphs that allow the overall risk to be compared by adversary, goal, or 
target (or building) or by any combination of the three. A facility manager can use these results to (1) identify the threats to which the system is most vulnerable, (2) assess whether protection is adequate, and (3) determine whether appropriate protective measures should be enhanced.

\section{Establishment of a Data Base}

Once we had developed our threat assessment approach and computer model, we assessed requirements input data using safeguards and security staff members at SAN and LINL. The individuals who participated in this assessment contributed expertise from their own areas of specialized knowledge to construct a preliminary data base. This data base had two purposes: it demonstrated the feasibility of the threat assessment approach, and it gave us the direction or focus for eliciting information from outside experts who could validate our assessment data.

As the project progressed, it hecame clear that data could be assessed at a less detailed level without changing the results of the analysis. This insight made our assessment of outside opinion more efficient because it allowed us to focus our attention on those judgements we deemed most critical to threat assessment.

\section{Validation of the Threat Assessment Data}

After we had completed our preliminary threat assessment, we identified those outside experts who could provide additional information or validate the judgement of project team members. To ensure that our communication with these experts was accurate and consistent, we developed questionnaires (see Appendix $A$ ) and assessment procedures. Then, we interviewed the identified experts and incorporated the information from these interviews into the model (Appendix B).

Because we had chosen to focus our interviews on the likelihood of threats, outside experts were asked to contribute only to the threat assessment input data, not to risk evaluation inputs. Specifically, we interviewed experts on terrorism, foreign governments, rziminal activity, and antinuclear extremist groups. In each case, our questions were limited to the motivations, goals, resources, and targets of each of these groups. Questions regarding safeguards capabilities or the consequences of successful threats-key inputs to the risk evaluation-were directed to appropriate DOE and facility experts.

\section{Application of the Approach}

We have used our threat likelihood assessment computer model to describe threats at a hypothetical site. In addition, we have combined consequence and safeguards effectiveness data in the risk evaluation to compute the overall risk posed by these threats.

The following paragraphs describe the types of nutputs and insights toined by using this model. The results should be viewed as tentative although the input data have been subjected to varying degrees of scrutiny: threat likelihood data have been verified by outside experts; safeguards and effectiveness information has been reviewed by DOE safeguards and security experts; and consequence judgments were made by project team members. Team members acknowledge that the verification process should be continued, as well as expanded in scope, to ensure that the asessment is both current and valid.

Figure 1 illustrates the model inputs and outputs summarized by adversary type. The first bar graph (Fig. 1a) shows threat likelihood, the output of the threat likelihood assessment. This figure suggests that the greatest likelihood of threats is from foreign governments and extremists. The next two bar graphs illustrate assessed data for relative consequences (Fig. $1 \mathrm{~b}$ ) and safeguards capabilities (Fig. 1c). Note that these reflect judgments that the relative consequences of threats are most severe from terrorists, foreign governments (Fig. 1b), and criminals and that terrorists and foreign governments will be the hardest to defeat (Fig. 1c). Figure 1d combines data from all three factors to illustrate that foreign governments and extremists pose the greatest overall risk.

Figure 2 shows illustrative results summarized by adversary goal. Goals related to the theft of SNM are broken down by quantity of material (Category I, Caiegory II, or sample) and by SNM in the form of a nuclear explosive-like assembly (NELA). Figure 2a, which displays threat likeijhood, indicates that the goal of most adversaries will be to penetrate and to steal information at applicable facilities. Figure $2 b$ shows, based on the consequence data, that theft of information represents the greatest overall risk. 

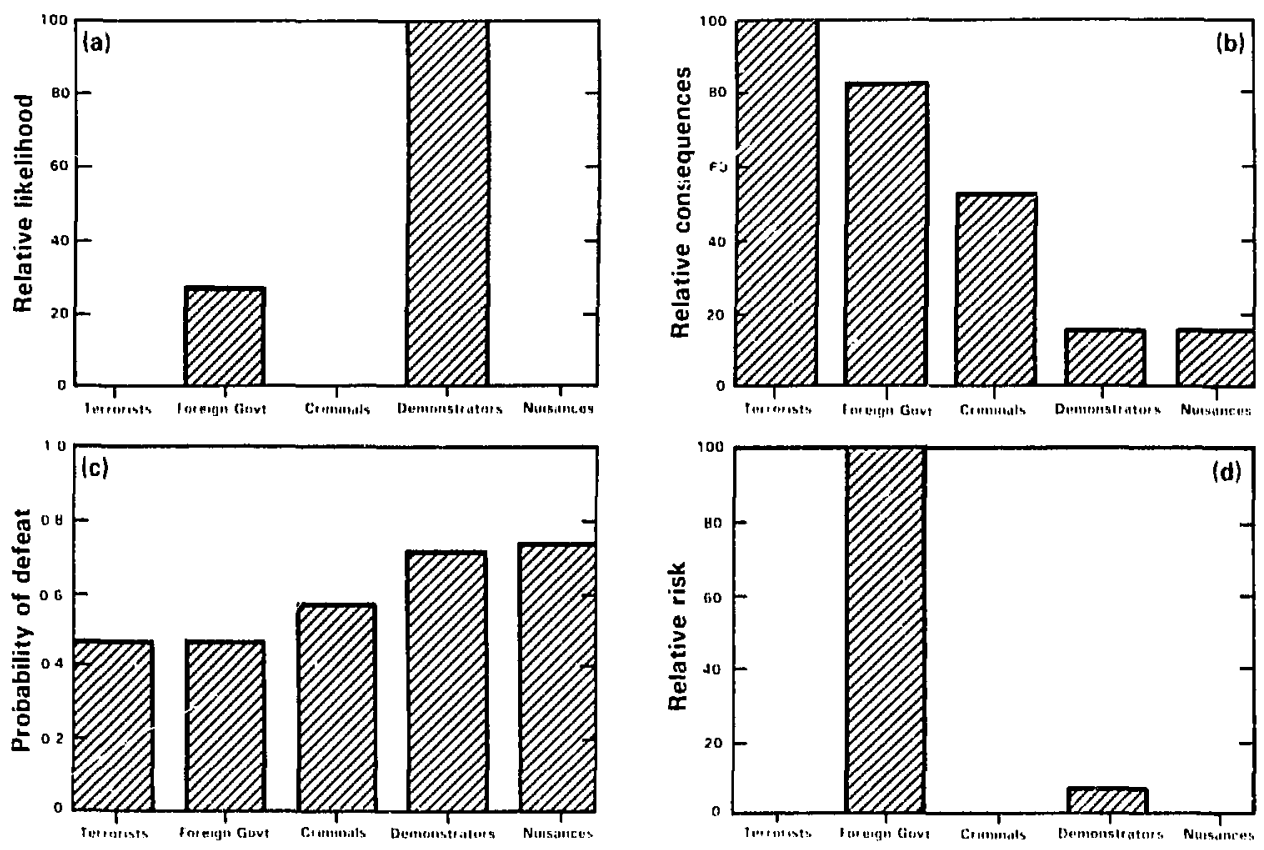

Figure 1. Threat likelihood (a), relative consequences (b), safeguards capabilities (c), and total risk (d) by adversary. The sole purpose of these data is to illustrate the types of outputs and insight to be gained from the approach.
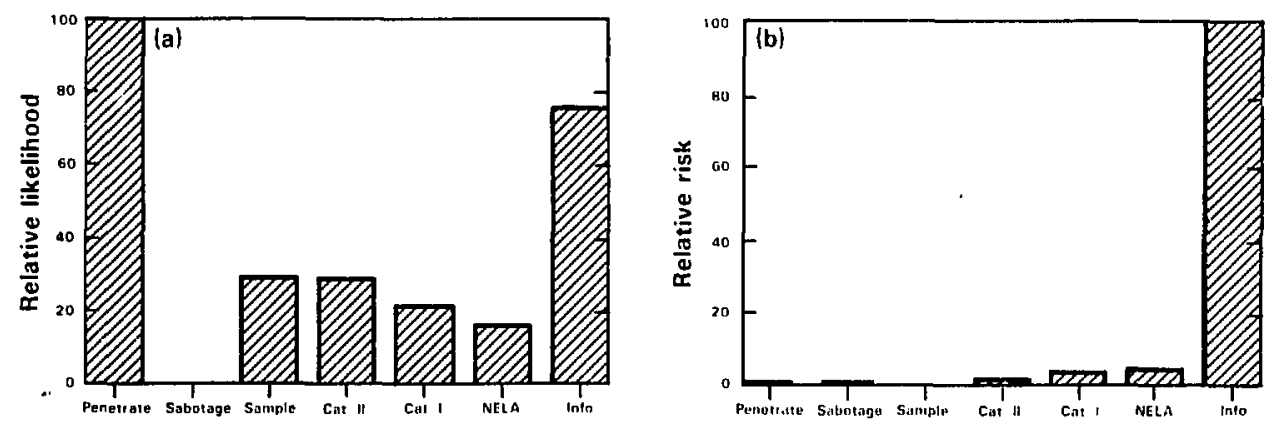

Figure 2. Threat likelihood (a) and total risk (b) by goal. 
Figure 3 provides a breakdown of risks for four representative buildings. The results indicate that adversary targets will be sensitive information in Bldg. A (Fig. 3a), Category 1 SNM in Bldg. B (Fig. 3b), sabotage, Category 2 SNM, and information in Bldg. $C$ (Fig. 3c), and information and Cateogry 1 SNM in Bldg. D (Fig. 3d).

Higure 4 illustrates how total risk may be apportioned by building. Since the greatest overall risk is due to the loss of information (Fig. 2b), Bldg. $A$ and other buildings containing classified documents and parts are dominant in Fig. 4.

To validate our preliminary data base, we compared our findings on the likelihood of threats by particular adversaries with the data obtained in interviews with outside experts. As Figure 5 shows, the pre- and post-interview data support the close correlation between the data base and threat assessment results.

On the basis of the DOE generic threat, the preponderance of current assessments and the corresponding application of resources have been directed toward thwarting the violent attack of a terrorist or criminal group aimed at the theft or misuse of SNM. This site-specific assessment, however, concludes that the greatest threat likelihood is not an overt attack on a facility. Rather, it cornes from foreign governments bent on the theft of sensitive information by acts of espionage. Evidence to support the credibility of this threat readily exists in the profusion of current espionage cases in this country. Defeating or neutralizing this threat, however, cannot be accomplished as handily as can its more visible counterparts. Indeed, little effort or resources have been expended in dealing with the subtlties of sensitive information loss.

"Representing areas containing classifled informition, SNM, and classified parls.
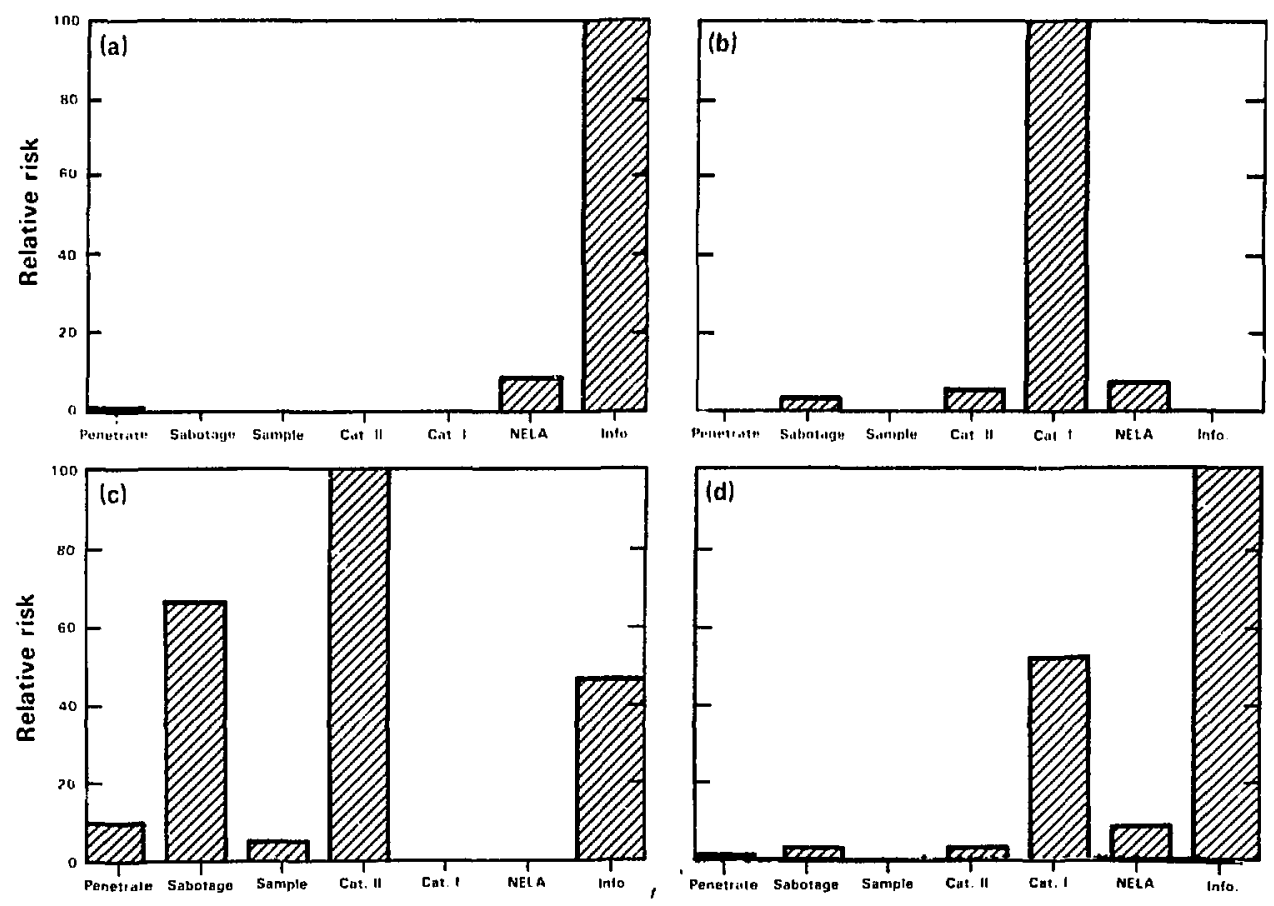

Figure 3. Total risk by builsing for Bldgs. $A(a), B(b), C(c)$, and $D(d)$. 


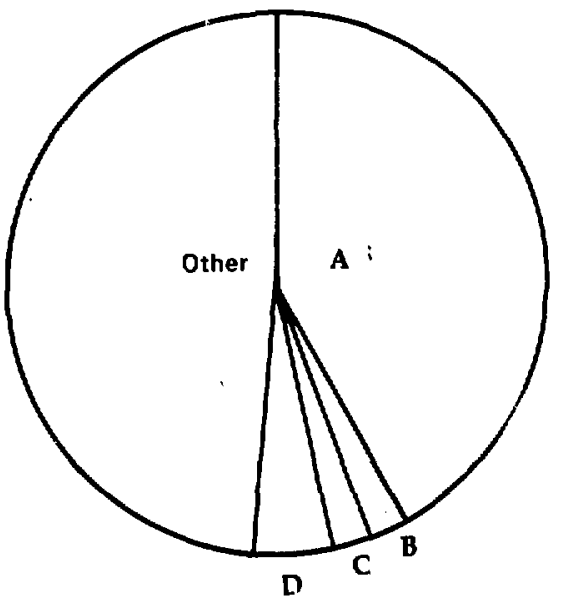

Figure 4. Total risk by building, showing the proportionate amount of risk represented by the buildings in Fig. 3.

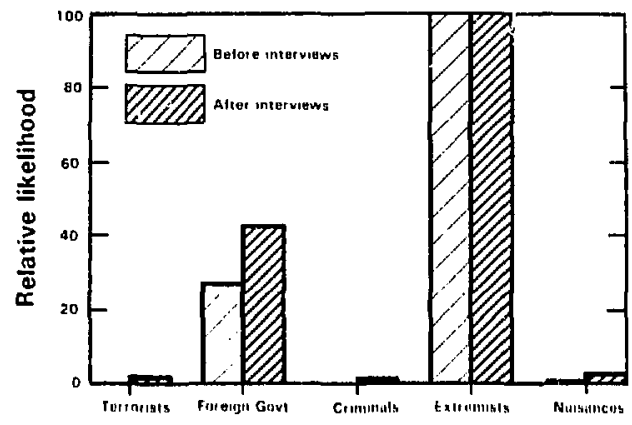

Figure 5. Pre- and post-interview assessments of threat likelihood by adversary.

\section{Conclusions}

Once we had developed and used our threat assessment approach to assess hypothetical threats, the next steps were to review the data with SAN and LLNL managers and, finally, to document and distribute our approach to facility managers at sensitive DOE sites. Encouraged by the close correlation between our original assessments of threat likelihood and data provided by the experts, we feel confident of our conclusion that the greatest threat likelihood is from foreign governments and extremists.

Although not subjected to the current validation process, two closely related conclusions may be drawn from the assessment process:

- Espionage by foreign governments poses the greatest overall risk to sensitive DOE facilities.
- The theft of sensitive information is a greater risk than the theft of SNM.

We intend to complete the documentation of our assessment technique to make it available to facility managers who face the challenges of protecting a sensitive facility. We hope that they will find it a practical tool for initiating their own local threat assessment.

Inquiries regarding this assessment may be directed to one of the team members at

Lawrence Livermore National Laboratory P.O. Box 808

Livermore, CA 94550

\section{Acknowledgments}

Outside experts contributing to this study were from the California Department of Justice, Sacramento, CA; the Central Intelligence Agency, Langley, VA; the Federal Bureau of Investigation, Washington, DC and Oakland, CA; the Los Angeles Police Department, Los Angeles, CA; and the U.S. Marshall's Service of McLean, VA. 


\section{Appendix A \\ Threat Assessment Questionnaire}

Organization:

Contributor:

Phone number:

Forward to: D. J. West

Lawrence Livermore National Laboratory

P.O. Box 808, L-503

Livermore, CA 94550 


\section{Threat Assessment Questionnaire}

\section{Introduction}

The U.S. Department of Energy has issued a generic threat guidance to describe the baseline threats that must be considered when designing safeguards and security systems or when assessing their performanre. DOE field offices, such as SAN, follow this generic guidance when assessing threats to their sites. However, threat assessment must also consider site-specific factors that may well pose an additional threat to these facilities.

\section{Overview of Threat Assessment Approach}

To ensure that threat assessments are conducted systematically, we have developed a quantitative approach for assessing the relative likelihood of potential threats at specific DOE sites, In assessing such likelihoods, we have considered information on a variety of adversaries, their primary motivations, their goals, and sites they might choose to accomplish their goals. Our approach divides this information into questions that can be answered by individuals who have relevant expertise. The answers to these questions will, in addition to providing input, provide a basis for determining the validity of the study and serve as a critique of the methodology used.

We will then use the data obtained to estimate the relative likelihood of specific poiential threats to selected DOE sites, using a computer model to display the relative likelihood of threats by adversary type or by adversary goal. The results will provide a consistent basis for evaluating risks and for making safeguards and security upgrade decisions.

\section{The Questionnaire}

This questionnaire is designed to elicit expert judgement regarding a spectrum of potential threats to DOE nuclear facilities, including those from adversaries such as terrorists, foreign governments, criminals, and anti-nuclear activists. For each of these adversary types, we consider a variety of motivations, goals, and sites they might choose to accomplish their missions.

We feel that this questionnaire is a critical step in developing a site-specific threat assessment and appreciate your personal assistance in this endeavor. 


\section{Threat Assessment Questionnaire Question 1}

1. Primary Motivation

(Adversary)

a. What do you consider primary motivations for this adversary?

Review the potential motivations listed in the table below. If necessary, expand the list. Place an $X$ in the column labeled Rank if the motivations listed are not appropriate for this adversary.

b. Rank the motivations.

Rank the primary motizations listed in the table in order of most likely (1) to least likely (3).

c. How likely is each motivation?

Express your judgement about the relative likelihood of each motivation using the following scale: very high (VH), high (H), medium (M), low (L), and very low (VL).

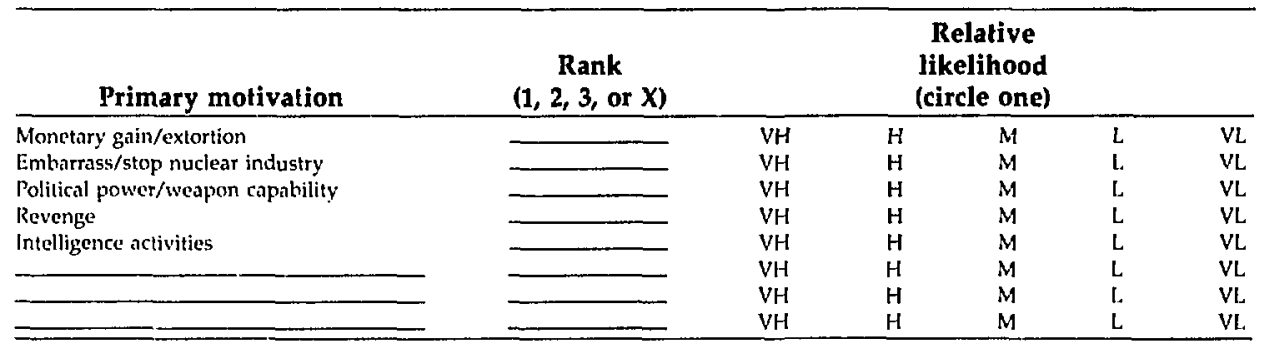

Rate your level of knowledge about this question (high, medium, low) 


\section{Threat Assessment Questionnaire \\ Question 2}

\section{Nuclear Facility $\frac{}{\text { (Adversary) }}$}

a. What is the likelihood that this adversary will target a United States nuclear facility, given each primary motivation?

The purpose of this question is to distinguish those adversaries who will attack a nuclear facility from those who may satisfy their primary motivation by some other means.

Complete the list of primary motivations to match the questionnaire.

Judge the relative likelihood that this adversary will choose a U.S. nuclear facility as a target, given that the adversary has each of the primary motivations listed in the table.

\begin{tabular}{|c|c|c|c|c|c|c|}
\hline \multirow{6}{*}{$\begin{array}{l}\text { Primary motivation } \\
\text { Monetary gain/extortion } \\
\text { Embarrass/stop nurlear industry } \\
\text { Political pou'er/weapon capability } \\
\text { Revenge } \\
\text { Intelligence activities }\end{array}$} & \multirow{3}{*}{$\begin{array}{c}\begin{array}{r}\text { Rank } \\
(1,2,3, \text { or } X)\end{array} \\
\end{array}$} & \multicolumn{5}{|c|}{$\begin{array}{l}\text { Relative } \\
\text { likelihood } \\
\text { (circle one) }\end{array}$} \\
\hline & & $\mathrm{VH}$ & $\mathrm{H}$ & $M$ & L & VL. \\
\hline & & $\mathrm{VH}$ & $H$ & $M$ & L & VL \\
\hline & 2 & $V_{H !}$ & $\mathrm{H}$ & $M$ & $\mathrm{~L}$ & $\mathrm{VL}$ \\
\hline & & VH & $\mathrm{H}$ & $M$ & L & $\mathrm{VL}$ \\
\hline & - & VH & $\mathrm{H}$ & $M$ & L. & VL \\
\hline \multirow{3}{*}{ 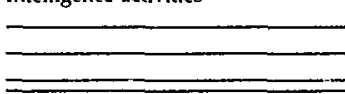 } & & VH & $\mathrm{H}$ & $\mathbf{M}$ & $\mathrm{L}$ & $\mathrm{VL}$ \\
\hline & & VH & $\mathrm{H}$ & $M$ & $\mathrm{~L}$ & VL \\
\hline & 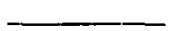 & VH & $\mathrm{H}$ & $M$ & $\mathrm{~L}$ & v!. \\
\hline
\end{tabular}

Rate your level of knowledge about this question (high, medium, low) 


\section{Threat Assessment Questionnaire \\ Question 3}

\section{California Facility}

a. Given this adversary's motivations and the target of a U.S. nuclear facility, what is the likelihood that the facility would be in California?

Complete the list of primary motivations for this adversary so that the following table matches the tables for Questions 1 and 2.

Judge the relative likelihood that this adversary will choose a nuclear facility in California given that the adversary is targeting a nuclear site. Provide this judgement for each of the primary motivations.

\begin{tabular}{|c|c|c|c|c|c|c|}
\hline \multirow{6}{*}{$\begin{array}{l}\text { Primary motivation } \\
\text { Monetary gain/extortion } \\
\text { Embarrass/stop nuclear industry } \\
\text { Political pu wrr/weapon capability } \\
\text { Revenge } \\
\text { Intelligence activities }\end{array}$} & \multirow{3}{*}{$\begin{array}{c}\begin{array}{c}\text { Rank } \\
(1,2,3, \text { or } X)\end{array} \\
\end{array}$} & \multicolumn{5}{|c|}{$\begin{array}{l}\text { Relative } \\
\text { likelihood } \\
\text { (circle one) }\end{array}$} \\
\hline & & VH & $\mathrm{H}$ & $M$ & L & VL \\
\hline & & VH & $\mathrm{H}$ & $M$ & L & VL \\
\hline & - & VH & $\mathrm{H}$ & M & L & VL \\
\hline & & VH & $\mathrm{H}$ & M & $\mathrm{L}$ & VL \\
\hline & 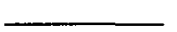 & VH & H & M & $\mathrm{L}$ & VL \\
\hline & & VH & H & $M$ & L & VL \\
\hline & - & VH & H & M & $\mathrm{L}$ & VL \\
\hline & 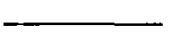 & $\mathrm{VH}$ & H & $M$ & $\mathrm{~L}$ & VL \\
\hline
\end{tabular}

Rate your level of knowledge about this question (high, medium, low) 


\section{Threat Assessment Questionnaire \\ Question 4}

\section{Goals}

Question 4 concerns possible goals-e.g., penetration of the facility or the acquisition of special nuclear material (SNM) - that adversaries might attempt to accomplish at a facility. These goals depend on the adversary's primary motivation. An adversary whose primary motivation is to embarrass the nuclear industry or to acquire high technology information is more likely to have a goal of merely penetrating the facility rather stealing SNM. On the other hand, an adversary whose primary motivation is the acquisition of political power/nuclear weapon capability will most likely have a goal of stealing SNM or a nuclear weapon.

Question 4 requires a separate form for each primary molivation that is considered likely. The assumption is that the answers given on each form will apply to any adversary having the listed primary motivation. 


\section{Threat Assessment Questionnaire \\ Question 4}

4. Goal

$\overline{\text { (Primary motivation) }}$.

a. What are the possible goals associated with this primary motivation and how likely is each? Review the potential goals listed in the table below. Place an $X$ in the column labeled Rank if the listed goal is not appropriate.

Note: Some of the goals refer to special nuclear materials (SNM), which includes plutonium and highly enriched uranium. Nuclear sabotage means causing a potentially injurious release of radioactive material to the environment.

b. Rank the goals.

Rank the goals listed in the table in order of most likely (1) to least likely (3).

c. How likely is each goal?

Assign relative likelihoods to each goal.

\begin{tabular}{|c|c|c|c|c|c|c|}
\hline \multirow{2}{*}{$\frac{\text { Goal }}{\text { Penetrate facility }}$} & \multirow{2}{*}{$\begin{array}{c}\text { Rank } \\
(1,2,3, \text { or } X) \\
\end{array}$} & \multicolumn{5}{|c|}{$\begin{array}{c}\text { Relative } \\
\text { likelihood } \\
\text { (circle one) }\end{array}$} \\
\hline & & VH & $\mathrm{H}$ & $M$ & $\mathrm{~L}$ & $\mathrm{VL}$ \\
\hline Acquire small amount of SNM & & VH & $\mathrm{H}$ & $\mathbf{M}$ & $\mathrm{L}$ & VL \\
\hline Acquire medium amount of SNM & & VH & $\mathbf{H}$ & M & $\mathrm{L}$ & VL \\
\hline Acquire weapen quantity of SNM & - & VH & $\mathrm{H}$ & M & $\mathrm{L}$ & $\mathrm{VL}$ \\
\hline Acquire nuclear weapon & 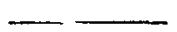 & VH & $\mathrm{H}$ & $M$ & L & $\mathrm{VL}$ \\
\hline Nuclear sabotage & $\longrightarrow$ & $\mathrm{VH}$ & $\mathrm{H}$ & M & t & $\mathrm{VL}$ \\
\hline
\end{tabular}

Rate your level of knowledge about this question (high, medium, low) 


\section{Threat Assessment Questionnaire Question 5}

\section{Site Selection}

Question 5 concerns the choice of possible nuclear sites in California that adversaries might select to achieve their goals. These sites differ depending on the type of operation and their role [commercial nuclear power, DOE weapons research and development (R\&D), weapons storage] and whether classified information, SNM, or nuclear weapons are present. Because of this variation in facilities, the choice of a site depends primarily on the adversary's goal; therefore, Question 5 requires a separate form for each goal. Again, the assumption is that the answers given on each form will apply to any adversary having the listed goal, regardless of the primary motivation.

Listed helow are possible sites that an adversary might choose with a specific goal in mind.

- Military facility-Nuclear weapons, information

- Nuclear power reactor-Radioactive material

- Transportation vehicle-Nuclear weapons or SNM

- Lawrence Livermore National Laboratory-R\&D for nuclear devices/SNM, information

- Sandia National Laboratory Livermore-R\&D for nuclear devices, information

- Atomics International's Energy Systems Gruup, Santa Suzanna (Los Angeles area)-SNM for reactors 


\section{Threat Assessment Questionnaire \\ Question 5}

\section{Site $\frac{}{\text { (Adversary goal) }}$}

\section{a. Which sites might $t$ an adversary with this goal attack?}

Review the sites listed in the table below. Place an $X$ in the column labeled Rank if the listed site is noi appropriate for this adversary.

b. Rank the sites.

Rank the sites listed in the table in the order of most likely (1) to least likely (3).

\section{c. How likely is each site?}

Assign relative likelihoods to each site. Express your judgement about the relative likelihoods qualitatively (high, medium, or low) or quantitatively. If you choose the quantitative approach, assign a value of 10 to the most likely site and proportionately lourer likelihoods to each of the other sites in the list.

\begin{tabular}{|c|c|c|}
\hline Site & $\begin{array}{c}\text { Rank } \\
(1,2,3, \text { or } X)\end{array}$ & $\begin{array}{l}\text { Relative } \\
\text { likelihood }\end{array}$ \\
\hline \multicolumn{3}{|l|}{$\begin{array}{l}\text { Military facility, (e.g., Concord } \\
\text { Naval Weapons Center) }\end{array}$} \\
\hline $\begin{array}{l}\text { Lawrence Livermore National Laborntor } \\
\text { Main Laboratory (nuclear R\&D) } \\
\text { Site } 300 \text { (test facility) }\end{array}$ & & \\
\hline Sandia National Laboratory Livermorc & & \\
\hline $\begin{array}{l}\text { Atomics Internationa! } \\
\text { Energy Systems Group }\end{array}$ & & \\
\hline Nuclear power reactor & & \\
\hline $\begin{array}{l}\text { Transportation vchicle for } \\
\text { nuclear weapons (SSTs) }\end{array}$ & & \\
\hline
\end{tabular}

Rate your level of knowledge about this question (high, medium, low) 
Input Data-Targets (provided by project team)

Select Site

QITE

Penetrate

Nuclear

Bample cat. II

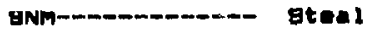

Babotage Bample cat. II Cat. I NEL.A Nuc. Info.

R\&D Facility

0.31

0.07

0.45

0.59

0.64

0.33

0.41

Select Building

DUILOING

Bultding $A$

Building $B$

Building $C$

Building D

кx 4 Other
Penotrate

Nuelear Babotage

100
10
60
15
185

30
40
100
50
20
200

220

$\begin{array}{rr}\text { Bample Cat. II } \\ 50 & 100 \\ 1 & 50 \\ 152 & 190\end{array}$

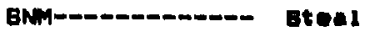

Cat. I NELA Nue, Info.

- 100

$30 \quad 20$

D

48

.

90

Input Data-Consequences (provided by project team)

Relative Consequences by Adversary

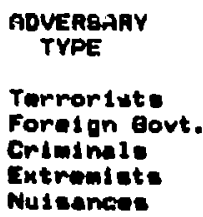

Relative Consequences by Building

$\begin{array}{rrrr}\text { Punatrate } & \begin{array}{r}\text { Nuclear } \\ \text { Eabotage }\end{array} & \text { Bample } & \text { Cat. II } \\ 100 & 100 & 100 & 100 \\ 100 & 100 & 100 & 10 \\ 100 & 100 & 100 & 60 \\ 10 & 100 & 100 & 10 \\ 10 & 100 & 100 & 10\end{array}$

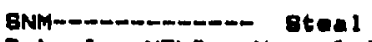

Cat. I NELA Nue. Info.

$\begin{array}{rrr}100 & 100 & 100 \\ 80 & 100 & 100 \\ 40 & 50 & 10 \\ 5 & 10 & 5 \\ 5 & 10 & 5\end{array}$

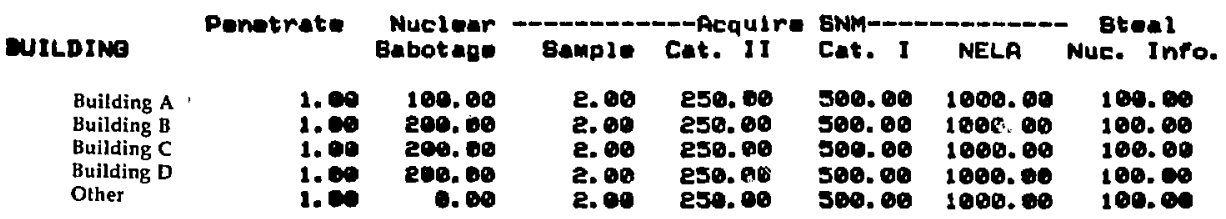


Input Data-Safeguards Capabilities (provided by project team)

Safeguard Capabilities-Bldg. A

\begin{tabular}{|c|c|c|c|c|c|c|c|}
\hline $\begin{array}{l}\text { ADVEFEAAY } \\
\text { TYPE }\end{array}$ & Panatrute & $\begin{array}{l}\text { Nuclear } \\
\text { gabotage }\end{array}$ & Bample & $\begin{array}{l}\text { C-Acquira } \\
\text { Cat. II }\end{array}$ & Canm- I & NEL & $\begin{array}{c}\text { bteal } \\
\text { Nuc. Infe }\end{array}$ \\
\hline $\begin{array}{l}\text { Terroriste } \\
\text { Foraign Bovt. } \\
\text { Criminass } \\
\text { Extremiets } \\
\text { Muleances }\end{array}$ & $\begin{array}{l}0.10 \\
0.10 \\
0.10 \\
0.10 \\
0.10\end{array}$ & $\begin{array}{l}0.11 \\
0.11 \\
0.11 \\
0.51 \\
0.51\end{array}$ & $\begin{array}{l}1.00 \\
1.00 \\
1.00 \\
1.00 \\
1.00\end{array}$ & $\begin{array}{l}1.00 \\
1.00 \\
1.00 \\
1.00 \\
1.00\end{array}$ & $\begin{array}{l}1.00 \\
1.00 \\
1.00 \\
1.00 \\
1.00\end{array}$ & $\begin{array}{l}0.60 \\
0.60 \\
0.76 \\
0.96 \\
0.96\end{array}$ & $\begin{array}{l}0.50 \\
0.50 \\
0.50 \\
0.50 \\
0.50\end{array}$ \\
\hline
\end{tabular}

Safeguard Capabilities-Bldg. B

\begin{tabular}{|c|c|c|c|c|c|c|c|}
\hline $\begin{array}{l}\text { ADVEREAAY } \\
\text { TVPE: }\end{array}$ & Penetruts & $\begin{array}{l}\text { Nuclear } \\
\text { Dabotage }\end{array}$ & gampla & $\begin{array}{l}\text {-Acquire } \\
\text { Cat. II }\end{array}$ & $\begin{array}{l}\text { BNM-D- } \\
\text { Cat. I }\end{array}$ & NELA & Nuc. Infe \\
\hline 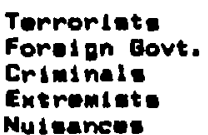 & $\begin{array}{r}0.10 \\
0.10 \\
0.50 \\
0.80 \\
0.95\end{array}$ & $\begin{array}{l}0.11 \\
0.11 \\
0.51 \\
0.80 \\
0.95\end{array}$ & $\begin{array}{l}0.56 \\
0.56 \\
0.15 \\
0.98 \\
1.00\end{array}$ & $\begin{array}{l}0.56 \\
0.56 \\
0.85 \\
0.98 \\
1.90\end{array}$ & $\begin{array}{l}0.36 \\
0.56 \\
0.85 \\
0.98 \\
1.00\end{array}$ & $\begin{array}{l}0.91 \\
0.91 \\
0.95 \\
0.99 \\
1.90\end{array}$ & $\begin{array}{l}0.50 \\
0.50 \\
0.50 \\
0.50 \\
0.50\end{array}$ \\
\hline
\end{tabular}

Safeguard Capabilities-Bldg. C

AbVEngaAY
TYPE
Terroricts
Foreign Dovt.
Criminale
Extremists
Nul oances

Penetrate

Nuclear Sample Cat. Il

$\begin{array}{lll}0.05 & 0.06 & 0.57 \\ 0.05 & 0.06 & 0.57 \\ 0.05 & 0.06 & 0.74 \\ 0.05 & 0.06 & 0.92 \\ 0.05 & 0.06 & 0.96\end{array}$

Q. 05

0. 05

๑. 86

0.57
0.57
0.74
0.92
0.96

0.57

D. 57

0.92

0.96
BNM--n-m-n-mel Cat. I NELA Nuc. Info.

$\begin{array}{lll}1.00 & 1.00 & 0.50 \\ 1.00 & 1.00 & 0.50 \\ 1.00 & 1.00 & 0.50 \\ 1.00 & 1.00 & 0.50 \\ 1.00 & 1.00 & 0.50\end{array}$

Safeguard Capabilities-Bldg. D

ADVEREAAY
TVPE

Penetrate

$\begin{array}{ll}0.05 & 0.60 \\ 0.05 & 0.60 \\ 0.20 & 0.21 \\ 0.80 & 0.80 \\ 0.90 & 0.90\end{array}$

$-$

Bample Cat. II

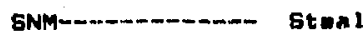

$\begin{array}{ll}0.76 & 0.57 \\ 0.72 & 0.57 \\ 0.8 B & 0.78 \\ 0.99 & 0.99 \\ 1.90 & 1.80\end{array}$

0.57
0.57
0.71
0.99
1.00

0.57

0.57

0. 79

0.99

1. 00

0.70
0.70
0.70
0.95
0.99

Safeguard Capabilities-BIdg. XXX Other

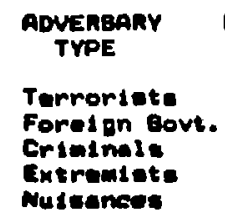

ADVEREARY

Penetrate

Nuclear Babotane

$\begin{array}{ll}0.05 & 0.06 \\ 0.05 & 0.06 \\ 0.05 & 0.06 \\ 0.05 & 0.06 \\ 0.05 & 0.06\end{array}$

Q. 06

0.06

0.06
BNM-Cat. I NELA Nuc. Info.

$\begin{array}{lllll}0.70 & 1.00 & 1.00 & 1.00 & 0.50 \\ 0.70 & 1.00 & 1.00 & 1.00 & 0.50 \\ 0.00 & 1.00 & 1.00 & 1.00 & 0.50 \\ 0.95 & 1.00 & 1.00 & 1.00 & 0.50 \\ 0.90 & 1.00 & 1.00 & 1.00 & 0.50\end{array}$


Computed Output

Threat Likelihood

AOVERLARY

TYPE

Terrorlete

Foreion Govt.

trininal:

Extremiete

Nulcances:

Sum

Norit. Dum
Penatrate Nuelear - -

Babotage

Gnim-_-

Nuc. Info

Nomellzed

Total

aOveneanY

TYPE

\section{rerroriete} Porelon Eovt. crieinale.

Extremites

Nuteances

Sum

torm. Bum

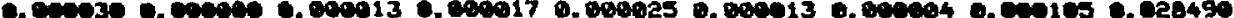

0.0003840 .0000000 .0001130 .0001760 .000935 0.000275 0.097375 0.099262 26.91384

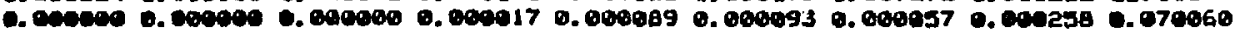

$0.171483 \quad 0.000421 \quad 0.050434 \quad 0.049176 \quad 0.035724 \quad 0.027774 \quad 0.03380 .368014$

0.0015i29 0.0004470 .0001470 .001160 0.000016 0.000404 0.002705 0.733486

$0.1734280 .0004220 .0510090 .049535 \cdot 0.0369350 .0281720 .131640 \quad 0.17342 \theta$

1000.24383529 .4124928 .3624521 .2979316 .2446475 .903160 .3660140 .471145
\end{abstract}

Total Risk

Penetrate Nuclear -

Gabotage gample Cat. Il Cat. I MELA Nuc. Info Total norm. Total

$0.00283 \quad 0.00112 \quad 0.00993 \quad 0.19063 \quad 0.55840 \quad 0.47125 \quad 0.019961 .245155$ 0.247540

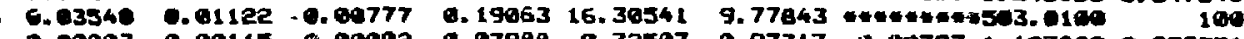

$\begin{array}{lllllllllll}0.00003 & 0.00115 & 0.00002 & 0.07988 & 0.32507 & 0.97317 & 0.02797 & 1.407280 & 0.279771\end{array}$

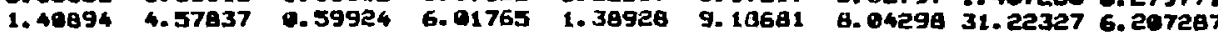

$0.012320 .00000 \quad 0.002360 .00774 \quad 0.00000 \quad 0.00511 \quad 0.09584$ 0.123362 0.024524

1.4595124 .5918620 .6103226 .48653218 .5791620 .41477494 .8679 .

0.3010120 .9470330 .125873 1.337793 3.83159.3 $4.210377 \quad 100503.0100537 .0691$ 
Computed Output

Tolal Risk-Blajg A NELA

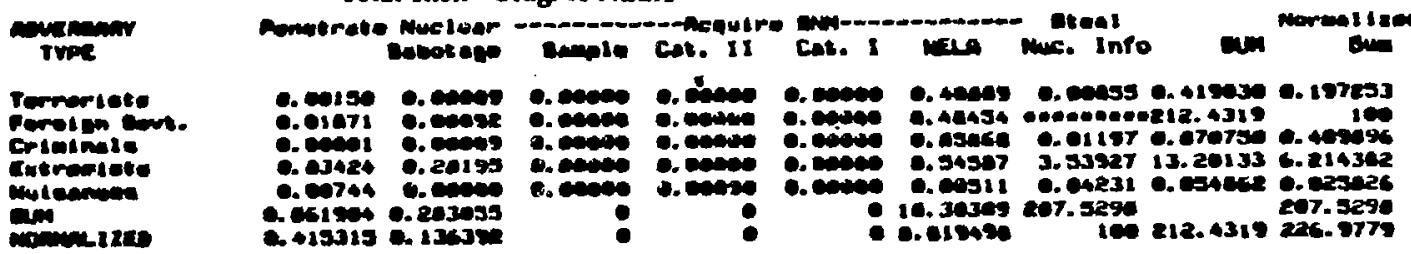

Tolal Risk-Bldg. B

emecomery

rvine

Torrortete Fereicen enve.

Criminela

Cutremiste

of

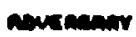

mpe

Termertete

Torelen Covs.

Crevinete

Cutrombete

Wuicemen

atrons

nonn-12ce

Gureanay

Trox:

termentete

rereace Evet.

Criminate

Entremiete

Mutenarese

nam

Winstires

$$
\text { Nevolear Eamie Cos. II }
$$

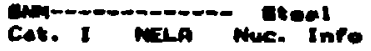

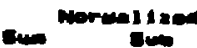

c. cenis

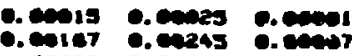

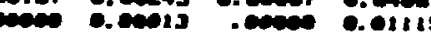

- Hias4 0.30645 0.6133 0.51765

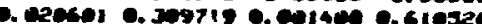

0.313350 .01040

. Isice 0.35180

c. sozis 0.027a9

Q. Sozso 0.427a?

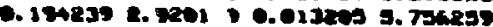

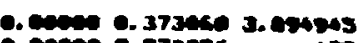

-. eceer 9.370us

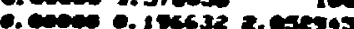

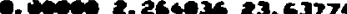
4.00431

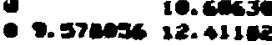

Total Rise-Bldg. C

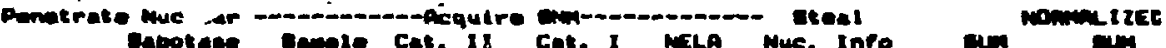

$$
\text { anootece ample cat. is }
$$

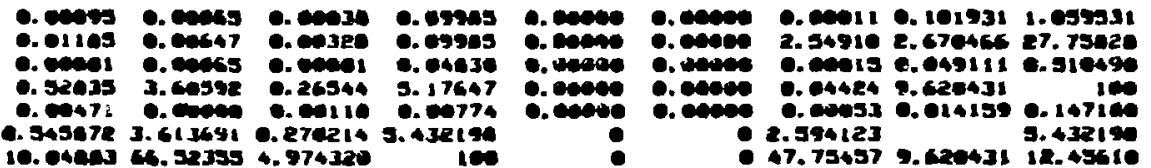

Total Risk-Bldg. D

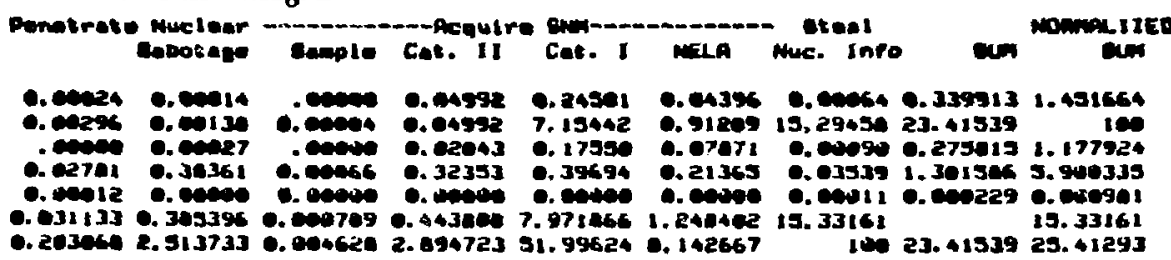

